\title{
Correction to: The role of NMR in leveraging dynamics and entropy in drug design
}

\author{
Abhinav Dubey ${ }^{1,4} \cdot$ Koh Takeuchi $^{2} \cdot$ Mikhail Reibarkh $^{3} \cdot$ Haribabu Arthanari ${ }^{1,4}$
}

Published online: 20 September 2020

(c) Springer Nature B.V. 2020

\section{Correction to: Journal of Biomolecular NMR https://doi.org/10.1007/s10858-020-00335-9}

Unfortunately, in the original publication, Fig. 5 was published incorrectly. The correct version is given below:

Publisher's Note Springer Nature remains neutral with regard to jurisdictional claims in published maps and institutional affiliations.

The original article can be found online at https://doi.org/10.1007/ s10858-020-00335-9.

Koh Takeuchi

koh-takeuchi@aist.go.jp

$\triangle$ Haribabu Arthanari

hari@hms.harvard.edu

1 Department of Cancer Biology, Dana-Farber Cancer Institute, Boston, MA 02215, USA

2 Cellular Molecular Biotechnology Research Institute \& Molecular Profiling Research Center for Drug Discovery (Molprof), National Institute of Advanced Industrial Science and Technology (AIST), Tokyo 135-0064, Japan

3 Analytical Research and Development, Merck \& Co., Inc., Rahway, NJ 07065, USA

4 Department of Biological Chemistry and Molecular Pharmacology, Harvard Medical School, Boston, MA 02115, USA 


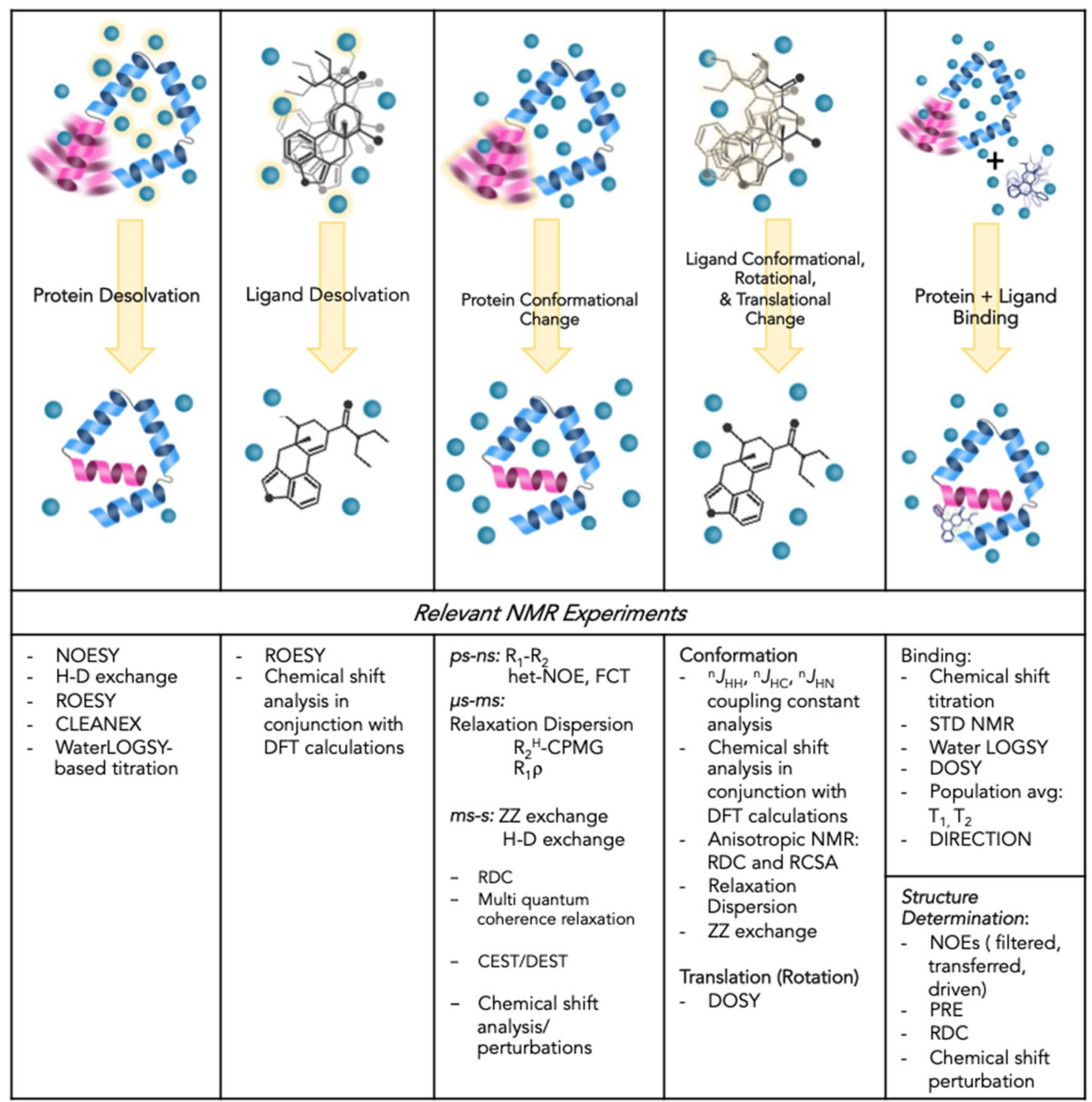

Fig. 5 An overview of the different components that contributes binding free energy in typical protein-ligand interaction and the relevant NMR experiments to study these individual contributions. It should be noted that some of methods would not provide absolute measurements of these thermodynamic quantities, rather relative measurements across a panel of lead compounds and their analogs 